\title{
Archives of Depression and Anxiety
}

\section{Álvaro Frías* \\ FPCEE Blanquerna, University of Ramon-Llull, Barcelona, Spain}

Dates: Received: 06 October, 2015; Accepted: 17 December, 2015; Published: 19 December, 2015

*Corresponding author: Alvaro Frías, Faculty of Psicologia, Ciencies de l'Educació i l'Esport Blanquerna, c/ Císter, 34, 08022, Barcelona, Spain, Tel: 0034 937417700; Fax: 0034 937417711; E-mail: afrias@csdm.cat

www.peertechz.com

\section{ISSN: 2455-5460}

Keywords: Attentional bias; Spider phobia; Virtua reality; Hypervigilance; Avoidance

\author{
Research Article
}

Different Patterns of Attentional Bias in Subjects with Spider Phobia: A Dot Probe Task using Virtual
Reality Environment

Abstract

Background: Cognitive theories posit that small animal phobics develop a hypervigilanceavoidance attentional pattern when coping with threat. However, empirical research has failed to obtain consistent results. We aimed at addressing this issue by diminishing the methodological flaws that hinder the internal and ecological validity of previous studies.

Methods: In this research, 34 spider fearful and 33 non-fearful participants completed a probe dot task using virtual reality environments. A subjective threshold for each participant was established. Position of the probe (low vs. up) and interval between trials (regular vs. irregular) were controlled.

Results: Compared to non-fearful individuals, spider phobics showed preconscious attentional bias towards threat in unexpected (low and irregular) trials. Moreover, phobics tended to display conscious attentional bias away from threat in unexpected (irregular) trials. Severity of fear did not correlate with attentional bias.

Limitations: We did not use eye movement tracking as well as potential biomarkers for attentional bias (e.g., event-related potentials). The risk of type-I error cannot be ruled out.

Conclusions: These findings partly support the hyper vigilance-avoidance pattern by considering some contextual factors that may enhance uncertainty in phobics. The alleged role of attentional bias in phobias is also questioned.

\section{Introduction}

Cognitive theories posit that attentional bias may play a role in the onset and maintenance of specific phobias [1,2]. Specifically, it has been postulated that patients' attentional processes are characterized by a hyper vigilance-avoidance pattern [3,4]. Accordingly, attentional bias towards threatening stimuli occurs when threat processing is automatic/preconscious and is away from them when threat processing is strategic/conscious. This implies that phobics initially direct their attention towards fear-relevant stimuli, followed by avoidance that is thought to prevent objective evaluation and habituation.

Because spiders are among the most common specific phobias, various experimental studies have been conducted in order to test this tentative model, most of them using a change detection paradigm [5]. Concerning this issue, empirical research has failed to show consistent findings regarding the time course of processing emotional stimuli so far [6-12]. It has been postulated that some contextual variables may account for these divergences, either the position of the dot or the regularity among trials. Preliminary data suggest that both factors may alter attentional bias by increasing the degree of uncertainty when individuals cannot predict the appearance of threats [13]. Moreover, research usually relies on an accurate threshold presentation (e.g., 100/200 milliseconds) to determine whether stimuli are detected by covert (preconscious) and/or overt (conscious) processing $[7,14]$. This methodological flaw precludes the determination of subjective threshold for each subject by assuming a generalized (objective) awareness threshold for the whole sample. Furthermore, the ecological validity of these studies is still inadequate, and most of them employ threatening pictures to assess phobia to spider rather than more realistic environments $[5,7,15]$. In this framework, virtual reality may be considered an alternative approach to enhancing the ecological validity from these studies by using more realistic, immersive, and interactive scenarios. To date, virtual reality has been mainly adapted to treat individuals diagnosed with different mental disorders such as anxiety disorders or eating disorders [1618]. However, its application in basic cognitive research is lacking.

\section{Aims and hypotheses}

Based on previous research, our study aimed at elucidating the time course of emotional processing of threat in individuals with spider phobia by increasing the internal and ecological validity of the results obtained. We hypothesized that phobic individuals, relative to nonphobic controls, will display a preconscious attentional bias towards threatening stimuli as well as a conscious attentional bias away from threatening stimuli. In addition, we postulate that this result will be altered by the degree of uncertainty and uncontrollability concerning the appearance and position of the threatening stimuli. That is, phobic individuals will exhibit enhanced preconscious attentional bias towards as well as increased conscious attentional bias away 
from threatening stimuli when these appear at irregular (vs. regular) intervals. Similarly, the position of the threatening stimuli will affect phobic individuals by enhancing both types of attentional bias when the threat appears more away from the straight view. As indicated by some authors, threats located on the "lower" side would appear more away from the straight view than threats located on the "upper" side $[3,19]$. In addition, there will be a positive relationship between the severity of phobia and attentional bias according to cognitive theories of anxiety disorders. Overall, we expect that our results will confirm the hypervigilance-avoidance pattern.

\section{Method}

\section{Participants}

The participants were undergraduate and postgraduate students recruited via advertisements at local universities placed in Valencia and Castellon (Spain) over two academic courses. The clinical sample was comprised of individuals diagnosed with spider phobia $(\mathrm{N}=34)$ according to DSM-IV criteria [20], and were compared with nonphobic control individuals $(\mathrm{N}=33)$. Diagnostic confirmation was made by independent researchers (clinical psychologists) who were blind to the hypothesis. Individuals $(n=2)$ with visual deficits affecting task performance (e.g., hypermetropia) were ruled out. Mean age for the whole sample was 25.93 ( $S D=4.77$, range $=19-35$ years), and most of them $(88 \%)$ were women. There were no between-group differences regarding age $(t=.47, \mathrm{df}=49, p=.39$, Cohen's $d=.42)$, gender $\left(\hat{k}^{2}=2.78\right.$, $\mathrm{df}=1, p=.35$, Cramer's $V=.25)$, marital status $\left(\aleph^{2}=3.01, \mathrm{df}=3, p=.21\right.$, Cramer's $V=.32)$, or educational attainment $\left(\aleph^{2}=3.45, \mathrm{df}=3, p=.13\right.$, Cramer's $V=.35$ )

\section{Questionnaires}

- The Anxiety Disorders Interview Schedule for DSM-IV (ADIS-IV) [21], is a structured interview designed to assess for current episodes of anxiety disorders, and to permit differential diagnosis among the anxiety disorders according to DSM-IV criteria. The ADIS-IV was used to make a categorical diagnosis of specific phobia (spider phobia) for those who were included in the clinical group. In addition, we employed this clinical interview to rule out this diagnostic among those who were included in the control group. The ADIS-IV has demonstrated good psychometric properties [22].

- The State-Trait Anxiety Inventory (STAI) [23], is a self-report inventory based on a 4-point Likert-type response options. The STAI consists of 40 questions that measure transient (STAI-E) and permanent (STAI-R) anxiety. The STAI presents adequate psychometric properties [24].

- The Fear of Spiders Questionnaire (FSQ) is an 18-item selfreport questionnaire assessing spider phobia based on a 7-point Likert-type response options [25]. The FSQ has excellent psychometric properties [26].

\section{Experimental procedure}

The Pentium III with $600 \times 400$ pixels was used. After completing the questionnaires, individuals were sitting 30 centimetres away from the monitor. The virtual scenario used was an uninhabited house in which the individuals may initially move anywhere inside (living, kitchen, restroom) through the keyboard buttons over 5 minutes. Some objects could be manipulated and heard when moved (e.g., closing/opening doors). Before starting the experiments, individuals were asked to follow a signal that guided them to a lighted room with some antique objects (e.g., woods, table) (Figure 1). The objective of all these was to increase the feeling of familiarity and absorption (realism) within the virtual environment.

In the first part, we sought to determine the subjective threshold for each subject via the "method of limits." Accordingly, a set of stimulus intensities was alternatively displayed in four ascendant and four descendant series over 10 trials. Stimuli employed were neutral (e.g., a star or a circle.) and were displayed on the front wall of the room. For each series, the turnaround was determined when individuals were no longer able to detect the neutral stimulus. The subjective threshold for each subject was calculated as the average (milliseconds) of all of the turnarounds.

In the second part, we sought to determine potential attentional bias using a dot probe task through a virtual environment comparable to a real living room. Overall, 240 trials were performed. For each trial, a fixation point was immediately followed by the threatening stimulus (spider) and the neutral stimulus (clock). Then, the subject should detect a probe (key) that could appear either replacing the threatening or the neutral stimuli. Stimuli were in 3-D. Some independent variables were proportionally manipulated across the trials: threshold (subliminal/preconscious vs. supraliminal/ conscious), interval between trials (regular/3 seconds vs. irregular/26seconds), and position (up/front wall vs. low/floor) In subliminal trials stimuli were presented somehow lower than the subjective threshold for each participant, while in supraliminal trials stimuli were presented somehow higher than the subjective threshold as determined in the task cited above. An attentional-bias index was created for up to the eight conditions resulting from the interaction among the three independent variables when considered all together.

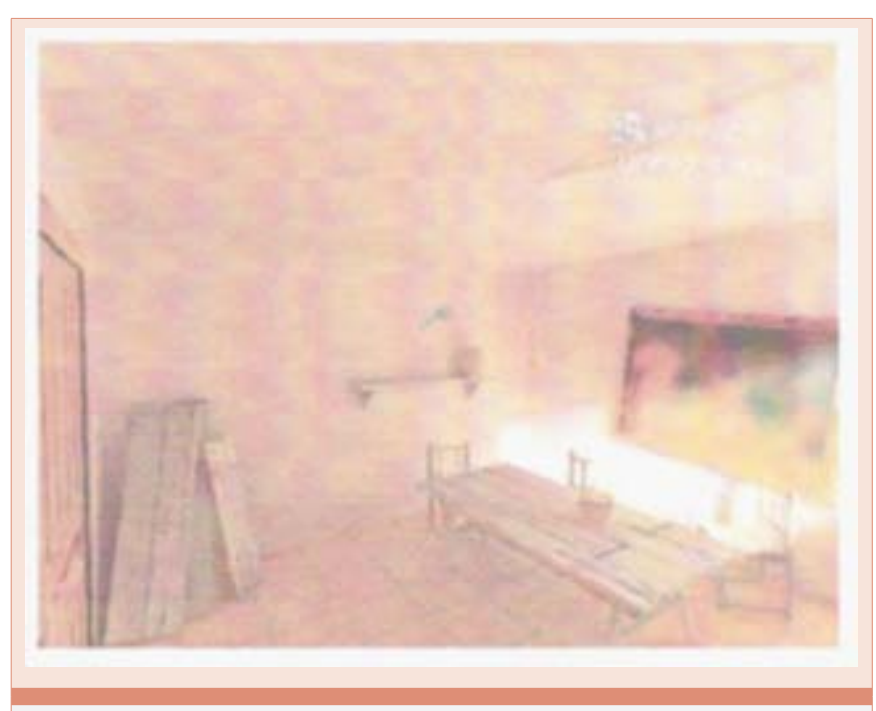

Figure 1: Dot probe task to assess spider phobia using virtual environment. 
Attentional-bias indices were defined as follows: 0,5 $x(T L P U+T U P L$

- TUPU - TLPL) $(\mathrm{T}=$ threat, $\mathrm{L}=$ low, $\mathrm{P}=$ probe, $\mathrm{U}=$ up $)$ [27]. Positive scores represent attentional bias towards the threatening stimuli. Values were based on reaction times (seconds) for correct responses, that is, excluding outliers ( $>2 S D$ ) and omissions ( $>0.150$ seconds) Overall, the percentage of outliers and omissions did not exceed $5 \%$ and $0.5 \%$, respectively. Likewise, there were no differences between both groups in number of omissions $(\mathrm{t}=.848, p=.27)$ and outliers $(\mathrm{t}=.391, p=.11)$.

\section{Statistical analysis}

Statistical analyses were performed using the Statistical Package for the Social Sciences (SPSS for Windows, Version 15.0). To look for between-group differences on confounders (e.g., sociodemographic data), we used parametric (Student's $t$ Test) for continuous variables and chi-square for categorical variables. To assess whether betweengroup differences on attention were modulated by other withinsubject variables (threshold and/or interval between trials and position), repeated-measures of multivariate analyses of variance (MANOVA) were also conducted. Observed power and effect size $\left(\right.$ partial $\eta^{2)}$ for each MANOVA analysis were also indicated. Pearson correlation was also conducted to assess the relationships between clinical measures and attentional-bias indices for the whole sample in general and phobic individuals specifically. $P$ values of less than .05 were considered significant. Values were presented as mean and plus/minus $S D$.

\section{Results}

\section{Comparison between phobic and non-phobic individuals in clinical measures}

Phobic individuals scored significantly higher than non-phobic individuals in FSQ $(t=31.93, \mathrm{df}=34, p<.001$, Cohen's $d=.62)$ Strikingly, there were no between-group differences in STAI-E $(t=1.99, \mathrm{df}=49, p=.23$, Cohen's $d=.24)$ and STAI-R $(t=0.47, \mathrm{df}=42$, $p=.19$, Cohen's $d=.35$ ). For both groups, STAI-E and STAI-R scores fell into the low range. Descriptive statistics are summarized in Table 1.

\section{Comparison between phobic and non-phobic individuals in attentional-bias indices}

First, phobic and non-phobic subjects did not differ in the subjective threshold ( $t=0.87, \mathrm{df}=59, p=.69$, Cohen's $d=.22$ ).

Then, repeated-measures MANOVA analyses were performed to seek for significant interaction effects between "group" and each within-subject variable ("threshold", "interval between trials", "position"), separately. There was only one interaction effect for "group x position" $\left(F(1,43)=6.65, p=.01\right.$, partial $\eta^{2}=.03$, power $=.81$, Wilks $\lambda=.94$ ) Compared with non-phobic subjects, phobic individuals showed higher attentional bias towards the threatening stimuli when the probe appeared "low" (vs. "up") $(F(2,42)=7.61, p=.002$, partial $\eta^{2}=.05$ ). Relative to phobic subjects, non-phobic individuals exhibited higher attentional bias towards the threatening stimuli when the probe appeared "up" (vs. "low") $F(2,42)=6.53, p=.01$, partial $\eta^{2}=.03$ ) (Figure 2). There was no other main or interaction effect.
Despitewe did notfind a significant "group x threshold" interaction, we performed further analyses to verify whether this interaction could be affected by additional variables. Accordingly, interactions between "group $\mathrm{x}$ threshold $\mathrm{x}$ position", "group $\mathrm{x}$ threshold $\mathrm{x}$ interval between trials", and "group $\mathrm{x}$ threshold $\mathrm{x}$ interval between trials $\mathrm{x}$ position" were carried out using repeated-measures MANOVA. Of interest, an almost significant "group $\mathrm{x}$ threshold $\mathrm{x}$ position" interaction was found $\left(F_{(2,42)}=3.49, p=.07\right.$, partial $\eta^{2}=.03$, power $=.79$, Wilks $\lambda=.86$ ). Specifically, we found that phobic individuals, relative to non-phobic individuals, showed significantly higher attentional bias towards the threatening stimuli when trials were "subliminal and low" $(F(1,43)=-$ 2.27, $p=.02$, partial $\eta^{2}=.04$ ) and also tended to display a higher attentional bias away from the threatening stimuli when trials were "supraliminal and up" $\left(F(1,43)=1.89, p=.06\right.$, partial $\eta^{2}=.03$ ) (Table 2). Besides, phobic individuals, relative to non-phobic subjects, exhibited significantly higher attentional bias towards threat when trials were "subliminal, irregular, and low" $\left(F(2,42)=2.63, p=.01\right.$, partial $\left.\eta^{2}=.05\right)$ and also manifested significantly greater attentional bias away from threat when trials were "supraliminal, irregular, and up" $(F(2,42)=-$ 2.09, $p=.04$, partial $\eta^{2}=.04$ ) In spite of these last findings, MANOVA analysis did not yield a significant interaction "group $\mathrm{x}$ threshold $\mathrm{x}$ interval between trials x position" $\left(F_{(1,43)}=2.12, p=.27\right.$, partial $\eta^{2}=.03$, power $=.81$, Wilks $\lambda=.85$ ).

Table 1: Clinical Comparison between phobic and non-phobic subjects.
\begin{tabular}{|l|l|l|l|l|}
\hline Scales & $\begin{array}{l}\text { Phobic } \\
\text { subject (N=34) } \\
\text { mean (SD) }\end{array}$ & $\begin{array}{l}\text { Non-phobic } \\
\text { subject (N=33) } \\
\text { (mean (SD) }\end{array}$ & Statistics & P values \\
\hline $\begin{array}{l}\text { FSQ (raw } \\
\text { score) }\end{array}$ & $98.17(10.44)$ & $8.10(8.14)$ & $t=31.935$ & 0.000 \\
\hline $\begin{array}{l}\text { STAI-E (raw } \\
\text { score) }\end{array}$ & $19.19(8.14)$ & $12.90(6.17)$ & $t=1.992$ & 0.232 \\
\hline $\begin{array}{l}\text { STAI-R (raw } \\
\text { Score) }\end{array}$ & $14.88(10.74)$ & $16.50(9.70)$ & $t=0.476$ & 0.190 \\
\hline
\end{tabular}

FSQ, Fear of Spiders questionnaire; STAI-E, State Teait Anxiety Inventorytransient symptoms; STAI-R, State Trait Anxiety Inventory-permanent symptoms.

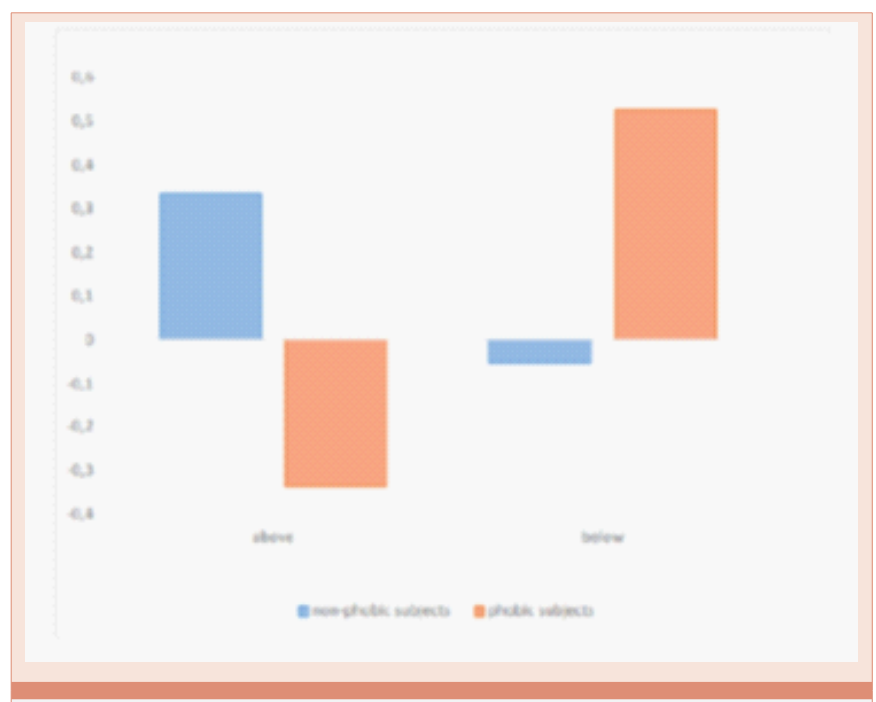

Figure 2: Differences in attentional blas between phobic and non-phobic subjects regarding position of the probe. 
Table 2: Comparison between phobic and non-phobic subjects in attentionalbias indices (seconds)

\begin{tabular}{|l|l|l|l|l|}
\hline & $\begin{array}{l}\text { Non-phobic } \\
\text { subjects } \\
\text { (N=33) } \\
\text { mean (SD) }\end{array}$ & $\begin{array}{l}\text { Phobic } \\
\text { subjects } \\
\text { (N=34) } \\
\text { mean (SD) }\end{array}$ & Statistics & P values \\
\hline Subliminal & $.002(.06)$ & $.02(.05)$ & $F=1.22$ & .14 \\
Supraliminal & $.01(.06)$ & $-.01(.05)$ & $F=1.45$ & .10 \\
\hline Subliminal-up & $.004(.05)$ & $.001(.04)$ & $F=.41$ & .45 \\
Subliminal-low & $-.003(.03)$ & $.02(.03)$ & $F=-2.27$ & .02 \\
Supraliminal-up & $.01(.04)$ & $-.01(.04)$ & $F=1.89$ & .06 \\
Subliminal-low & $.001(.02)$ & $.003(.04)$ & $F=.41$ & .47 \\
\hline Subliminal-regular & $.01(.03)$ & $.01(.02)$ & $F=.27$ & .71 \\
Subliminal-irregular & $-.003(.05)$ & $.01(.04)$ & $F=-1.25$ & .12 \\
Supraliminal-regular & $.01(.02)$ & $.004(.04)$ & $F=.85$ & .23 \\
Supraliminal-irregular & $-.003(.06)$ & $-.02(.04)$ & $F=-.94$ & .18 \\
\hline Subliminal-regular-up & $.51(2.72)$ & $.15(2.66)$ & $F=1.12$ & .15 \\
Subliminal-regular-low & $-.04(2.16)$ & $.46(1.55)$ & $F=-1.28$ & .1 \\
Subliminal-irregular-up & $-.05(3.99)$ & $-.09(2.55)$ & $F=-.68$ & .29 \\
Subliminal-irregular-low & $-.25(2.11)$ & $1.34(2.84)$ & $F=2.63$ & .01 \\
Supraliminal-regular-up & $.5(1.88)$ & $-.01(2.29)$ & $F=1.09$ & .18 \\
Supraliminal-regular-low & $.73(1.46)$ & $.43(2.82)$ & $F=.93$ & .2 \\
Supraliminal-irregular-up & $.37(3.76)$ & $-1.36(2.5)$ & $F=-2.09$ & .04 \\
Supraliminal-irregular-low & $-.65(2.46)$ & $-.12(2.46)$ & $F=-1.02$ & .17 \\
\hline
\end{tabular}

\section{Relationship between attentional-bias indices and clinical measures}

First, we conducted Pearson's correlation to assess potential relationships among attentional-bias indices. There was a negative trend between "supraliminal" and "subliminal" indices for the whole sample ( $r=.26, \mathrm{df}=65, p=.08)$ Particularly, there was a significant negative relationship between "supraliminal" and "subliminal" indices among phobic individuals $(r=-.47, \mathrm{df}=65, p=.02)$. This means that the participants with higher attentional bias towards threat in the subliminal condition had lower attentional bias away from the threat in the supraliminal condition, and vice versa. The more specific attentional-bias indices did not yield any significant correlation.

Furthermore, we looked for potential relationships between FSQ scores and attentional-bias indices. FSQ did not significantly correlate with almost any attentional-bias index for the whole sample, with the exception of the "subliminal and low" index $(r=.30, \mathrm{df}=65, p=.04)$. Within phobic individuals, we only found a significantly negative correlation between FSQ scores and "supraliminal, irregular, and low" index ( $r=-.47, \mathrm{df}=65, p=.03)$.

\section{Discussion}

This study sought to establish the time course of attentional bias in spider phobia individuals by improving the internal as well as the ecological validity. Overall, our findings in a more realistic environment partly support the hyper vigilance-avoidance pattern, depending on some contextual variables taken into consideration. These modulating variables may also account for some differences between previous similar studies using the dot probe task.

First, we did not obtain significant differences between groups when we only consider "threshold" (supraliminal vs. subliminal). Hence, phobic and non-phobic subjects did not differ on attentional bias irrespective of whether the threatening stimulus were presented somehow lower or higher than the subjective threshold for each participant. This result contradicts our main hypothesis concerning the hypervigilance-avoidance pattern. However, when "position" (up vs. low), and "interval between trials" (irregular vs. regular) were included in the analysis, the study partly support the hypervigilanceavoidance pattern in phobic individuals when compared with nonphobic subjects. Concretely, hypervigilance was observed in both "subliminal and low" and "subliminal, irregular, and low" trials, whereas an avoidance trend was identified in either "supraliminal and up" or "supraliminal, irregular, and up" trials. In spite of this, MANOVA analyses were not significant and the risk of type-I error cannot be ruled out. A potential attentional dissociation in phobic individuals was also confirmed by a significantly negative correlation between subliminal and supraliminal attentional-bias indices. Overall, these data are in accordance with several studies given more compelling support to preconscious hypervigilance than strategic attentional avoidance in animal phobia individuals $[6,7,14]$.

Second, uncertainty concerning the appearance of threats (as measured by "irregular" intervals) and uncontrollability concerning the location of threats (as measured by "low" position) increased attentional bias only in phobic individuals. This result supports our hypothesis and indicates to what extent uncertainty and uncontrollability may alter the attentional bias in phobic individuals probably by increasing anxiety-related levels. This statement is partly in line with one study in which uncertainty (not sure where a spider is going to be present) enhanced attentional scrutiny for both threatening and neutral/irrelevant stimuli in phobic individuals [28]. That is, uncertainty led to generalized hypervigilance when phobics were not able to predict the appearance of threats. Moreover, another study with animal phobia individuals also revealed that uncertainty (not sure where a spider is going to be located) increased attentional bias towards the threat in phobics and healthy controls [13]. Contrary to this last finding, our control individuals exhibited higher attentional bias towards threat when conditions were more predictable and controllable ("regular" and/or "up" trials).

Third, we also observed that non-phobic individuals tended to show an attentional bias towards threat. Concerning this issue, we consider that spiders represent evolutionary threats and attentional bias among the general population was developed to help humans to detect these threatening stimuli for a long time [29]. In fact, research on general population indicates attentional capture by phylogenetically fear-relevant animal stimuli and the selective enhancement of this effect by fear of these animals [30].

Fourth, we did not obtain enough evidence confirming a relationship between severity of fear and attentional bias indices. This result contradicts our hypothesis as well as some previous research [5]. Based on our finding, we can suggest that attentional bias may be an epiphenomenon rather than a vulnerability factor in spider phobia. In accordance with this statement, some clinical trials have found that improvements through attention training do not reduce severity of fear in small animal phobics [31,32].

\section{Strengths and weaknesses}

This study has several strengths. Unlike most previous research, we recruited clinical individuals rather than analogue individuals. 
Sample size was also appropriate and was larger than most studies using the dot probe task. Moreover, subjective threshold was established for each participant. Furthermore, we controlled for some potential modulating variables involved in task performance such as "position" and "interval between trials." Finally, we used a virtual environment to enhance ecological validity.

This study has also some weaknesses. We did not use eye movement tracking [4,33-35]. Hence, we cannot rule out that phobics exhibit difficulty in disengaging from threat rather than faster reaction times when the threat appears. Moreover, we did not include any neurobiological measure as potential biomarker for attentional bias [36-38].

By including some neuroimaging/neurophysiological procedures we could determine whether preconscious hypervigilance and strategic attentional avoidance in animal phobia individuals imply different biological pathways. Finally, because MANOVA analyses were not significant, we cannot exclude the risk of type-I error when displaying the main findings of the current study.

\section{Conclusions}

- Phobics and non-phobics individuals differ regarding attentional bias.

- A hypervigilance-avoidance pattern of attentional-bias is partly supported in individuals with spider phobia.

- Contextual factors affecting uncertainty and uncontrollability should be considered in phobics' attentional bias.

- Attentional bias towards threat is a normal reaction when the threatening stimuli are expected.

- Attentional bias may be an epiphenomenon rather than a vulnerability factor in individuals with spider phobia.

\section{References}

1. Kindt M, Brosschot JF (1999) Cognitive bias in spider-phobic children Comparison of a pictorial and a linguistic spider Stroop. Journal of Psychopathology and Behavioral Assessment 21: 207-220.

2. Lavy E, van den Hout MA, Arntz A (1993) Attentional bias and spider phobia Conceptual and clinical issues. Behavior Research and Therapy 31: 17-24.

3. Hermans D, Vansteenwegen D, Eelen P (1999) Eye movement registration as a continuous index of attention deployment: Data from a group of spider anxious students. Cognition and Emotion 13: 419-434.

4. Huijding J, Mayer B, Koster EH, Muris P (2011) To look or not to look: An eye movement study of hypervigilance during change detection in high and low spider fearful students. Emotion 11: 666-674.

5. Lipp OV, Derakshan N (2005) Attentional bias to pictures of fear-relevant animals in a dot probe task. Emotion 5: 365-369.

6. Cisler JM, Ries BJ, Widner RL, Jr. (2007) Examining information processing biases in spider phobia using the rapid serial visual presentation paradigm. Journal of Anxiety Disorders 21: 977-990.

7. Mogg K, Bradley BP (2006) Time course of attentional bias for fear-relevan pictures in spider-fearful individuals. Behavior Research and Therapy 44 : 1241-1250.

8. Ohman A, Soares JF (1994) Unconscious anxiety: Phobic responses to masked stimuli. Journal of Abnormal Psychology, 103, 231-240.
9. Pflugshaupt T, Mosimann UP, von Wartburg R, Schmitt W, Nyffeler T, et al. (2005) Hypervigilance-avoidance pattern in spider phobia. Journal of Anxiety Disorders 19: 105-116.

10. Rinck M, Becker ES (2006) Spider fearful individuals attend to threat, then quickly avoid it: Evidence from eye movements. Journal of Abnormal Psychology 115: 231-238

11. Thorpe SJ, Salkovskis PM (1997) Information processing in spider phobics: The Stroop colour naming task may indicate strategic but not automatic attentional bias. Behavior Research and Therapy 35: 131-144.

12. Van den Hout M, Tenney N, Huygens K, de Jong P (1997) Preconscious processing bias in specific phobia. Behavior Research and Therapy 35: 2934.

13. Vrijsen JN, Fleurkens P, Nieuwboer W, Rinck M (2009) Attentional bias to moving spiders in spider fearful individuals. Journal of Anxiety Disorders 23: 541-545.

14. Sebastiani L, Castellani E, Dalessandro L (2010) Fear-object perception: Does it entail the involuntary capture of attention? Archives Italiennes de Biologie 148: 33-42.

15. Okon-Singer H, Alyagon U, Kofman O, Tzelgov J, Henik A (2011) Fearrelated pictures deteriorate the performance of university students with high fear of snakes or spiders. Stress 14: 185-193.

16. Baños R, Quero S, Perpiña C, Fabregat S (2004) Telepsychology and selfhelp: The treatment of phobias using the Internet. Cyberpsychology and Behavior 7: 272-273.

17. Ferrer-García M, Gutiérrez-Maldonado J (2012) The use of virtual reality in the treatment of eating disorders. Studies in Health Technology and Informatics 181: $17-21$

18. McCann RA, Armstrong CM, Skopp NA, Edwards-Stewart A, Smolenski DJ, et al. (2014) Virtual reality exposure therapy for the treatment of anxiety disorders: An evaluation of research quality. Journal of Anxiety Disorders 28: 625-631.

19. Pineles S, Mineka S (2005) Attentional biases to internal and external sources of potential threat in social anxiety. Journal of Abnormal Psychology 114: 314-318.

20. American Psychiatric Association (1994) Diagnostic and Statistical Manual of Mental Disorder (4a ed.) Washington, DC: Author.

21. Di Nardo PA, Brown TA, Barlow DH (1994) Anxiety Disorders Interview Schedule for DSM-IV: Lifetime Version, Client Interview Schedule. Oxford: Oxford University Press.

22. Brown TA, Di Nardo PA, Lehman CL, Campbell LA (2001) Reliability of DSMIV anxiety and mood disorders: Implications for the classification of emotional disorders. Journal of Abnormal Psychology 110: 49-58.

23. Spielberger CD, Gorsuch RL, Lushene RE (1970) Manual for the State-Trait Anxiety Inventory. Palo Alto, CA: Consulting Psychologists Press.

24. TEA (1982) Cuestionario de ansiedad estado-rasgo. Madrid: TEA Ediciones.

25. Szymanski J, O'Donohue W (1995) Fear of Spiders Questionnaire. Journal of Behavior Therapy and Experimental Psychiatry 26: 31-34.

26. Muris $\mathrm{P}$, Merckelbach $\mathrm{H}$ (1996) A comparison of two spider fear questionnaires. Journal of Behavior Therapy and Experimental Psychiatry 27: 241-244.

27. MacLeod C, Mathews A, Tata P (1986) Attentional bias in emotional disorders. Journal of Abnormal Psychology 95: 15-20.

28. Devue C, Belopolsky AV, Theeuwes J (2011) The role of fear and expectancies in capture of covert attention by spiders. Emotion 11: 768-775.

29. Ohman A, Mineka S (2001) Fears, phobias, and preparedness: Towards an evolved module of fear and fear learning. Psychological Review 108: 483522. 
30. Waters AM, Lipp OV (2008) The influence of animal fear on attentional capture by fear-relevant animal stimuli in children. Behavior Research and Therapy 46: 114-121.

31. Reese HE, McNally RJ, Najmi S, Amir N (2010) Attention training for reducing spider fear in spider-fearful individuals. Journal of Anxiety Disorders 24: 657662.

32. Van Bockstaele B, Verschuere B, Koster EH, Tibboel H, De Houwer J, et al. (2011) Effects of attention training on self-reported, implicit, physiological and behavioural measures of spider fear. Journal of Behavior Therapy and Experimental Psychiatry 42: 211-218.

33. Aue T, Hoeppli ME, Piguet C, Sterpenich V, Vuilleumier P (2013) Visual avoidance in phobia: Particularities in neural activity, autonomic responding, and cognitive risk evaluations. Frontiers in Human Neuroscience 7: 194.

34. Gerdes AB, Alpers GW, Pauli P (2008) When spiders appear suddenly:
Spider-phobic patients are distracted by task-irrelevant spiders. Behavior Research and Therapy 46: 174-187.

35. Pflugshaupt T, Mosimann UP, Schmitt WJ, von Wartburg R, Wurtz P, et al. (2007) To look or not to look at threat? Scanpath differences within a group of spider phobics. Journal of Anxiety Disorders 21: 353-366.

36. Britton JC, Gold AL, Deckersbach T, Rauch SL (2009) Functional MRI study of specific animal phobia using an event-related emotional counting Stroop paradigm. Depression and Anxiety 26: 796-805.

37. Leutgeb V, Schäfer A, Köchel A, Scharmüller W, Schienle A (2010) Psychophysiology of spider phobia in 8- to 12-year-old girls. Biological Psychology 85: 424-431.

38. Van Strien JW, Franken IH, Huijding J (2009) Phobic spider fear is associated with enhanced attentional capture by spider pictures: A rapid serial presentation event-related potential study. Neuroreport 20: 445-449. 